The Pharmacopoeia directs an ounce of phosphorus (price at least 2s. 6d.), nitric acid four fluid ounces pure (price 1 s.), consequently the materials cost $3 \mathrm{~s}$. 6d., independently of the apparatus; viz., retort, sandbath, and an evaporating capsule of platina, which is the most expensive article of the whole. If we take the equivalent of phosphorus at $31.4,1$ oz. 480 grs. $\div 31.4=$ 15.3 equivalents nearly; each of which combined with 5 of oxygen $=40 \times 15.3=$ 612 grs. of real phosphoric acid as the result: the dilution of course is arbitrary. Phosphate of lead consists of one equivalent of oxide of lead, or Ph. 103.7 + 08. = 111.7, and one of phosphoric acid 71.4 $+111.7=$ 183.1 , or, i.e., in round numbers, every 183 grs. of phosphate of lead would yield by decomposition $\mathbf{7 1 . 4}$ grs. of phosphoric acid : consequently we have $71: 183:: 612: 1576$ grrs. of phosphate of lead, which would yield as much phosphoric acid as the ousce of phosphorus. Phosphate of lead costs 6d. per ounce, consequently the salt would cost about 1s. 8d.; and allowing $2 d$. for the sulphuretted hydrogen, the phosphoric acid which costs 3s. 6d. by the Pharmacopoeia, may be had without any trouble for 1s. 10d.

My object, Mr. Editor, in thus trespassing on your time, is to inquire if you, or some of your chemical correspondents, will state, through the medium of THE LANCET, whether there be anything objectionable in the process I have just been advocating, as I cannot well comprehend why it did not supersede the apparently, at least, more difficult, objectionable, and expensive process in the Pharmacopoia. I am, Sir, your most obedient servant,

Mediculus nuperrime permissus.

London, March 21, 1842.

P.S.-I feel it right to observe, that $I$ first heard the above process recommended and illustrated by Dr. Venables. He also recommended substituting hydrochloric acid for the sulphuric acid, recommended by the college for liberating carbonic acid gas from marble or chalk, and to my mind upon good grounds; namely, that the resulting chloride of calcium will save the necessity of a distinct operation or process for its preparation.

\section{THE WATER-CURE QUACKERY.}

\section{To the Editor of THE LANCET.}

SIr,-Passing my eye over some old medical essays in my possession, published by a society in Edinburgh in 1744, $I$ find in vol. v., part 2 , p. 895 , some curious remarks, by John Stevenson, fellow of the College of Physicians, Edinburgh, in an essay on the cassse of animal heat, and on some of the effects of heat and cold on the human body. As at this time much noise is made amongst the public about " hydropathy, or the cold. water cure, said to be just now discovered by one "Vincent Priessnitz, of Graefenburgh, in Silesia," I think that you will be convinced, on perusing them, that the said Priessnitz is not the discoverer, or originater, of the practice; but that it is of ancient origin, was formerly recommended by the great Dr. Pringle, and, from its ineficacy and great danger, when indiscriminately used, was very properly allowed to fall into disuse, and is now revived, only to impose on a too credulous public, always eager to follow any empirical scheme that is offered to them by charlatans, to the detriment of the scientific practitioners of medicine. But there is an old saying, "that every dog has his day," and I have little doubt but that, ere long, hydropathy, as well as homoeopathy, and many other thies, will be entombed in the common gulf. I am, Sir, yours, very truly,

$$
\begin{aligned}
& \text { H. B. C. Hil } \\
& \text { 85, Grower-street, Bedford-square, } \\
& \text { A pril 18, 1842. }
\end{aligned}
$$

"One who was no physician, having read in a loose leaf of some old book that an obstinate constipation had been removed by throwing cold water on the feet, put it in practice in Holland on an acquaintance of his and mine, in a case of that kind, which had proved obstinate to all Dr. Boerhaave's applications for several days. I was at some pains in search of the author of this bint, but could find nothing like it, save the account that Brassavolus gives, of Savana. rola's curing the Duke of Ferrara of a three days' constipation, by making him walk barefooted on a cold wet marble floor.

"Though Brassavolus counts this a dangerous remedy, and not to be tried, because it may bring on gripes and a flux; and how. ever ridiculous the experiment may at first sight seem to be; I thought it so reasonable, and consonant to sound theory, that I still kept it in my eye, as well worth trying, when other means of opening the body failed; perhaps in the iliac passion itself. The rationale, at least the feasibleness of this cure will, I hope, appear, from reflecting on these few loose hints, the application of most of which is so obvious, that I shall hardly need to make it.

"There is nothing more common than colic pains and purging from cold wet feet. ' Cutis siccitas alvi laxitas,' is a well knowu aphorism. On a sudden check of the perspiration, the perspirable matter frequently makes a push at the guts, and brings on a diarrhoea : this seems to have an advanlage which neither purgatives taken by the mouth nor clysters have, or can have; for either of these can act only on one end of the hard excrement with which the gut is in a manner corked; whereas the matter of the wanctorian perspiration, checked by external 
cold, rushing into the cavity of the intestine, betwixt it and the faces, may, at once, lubricate the passage, dissolve part of the hard contents, and stimulate the gut to forward the egestion. In the small-pox, and other fevers, when there has been a long retention of urine, patients commonly get relief immediately after setting their feet on the cold ground. As cooling the feet forwards both the secretion and excretion of urine, it may have a similar effect on the bile. Most people incline to make water, and many are disposed to go to stool, on putting their feet into cold water, or even washing their hands with it; from a sort of tremor, shock, or stimulus induced on the nerves; taking off some inertia or sluggishness of the membranous system of the guts and bladder, which had disabled them from throwing off their loads. From what I have observed, on opening the bodies of some who have died of constipation, and the ileus itself, I am apt to believe, that frequently these ailments are, first or last, owing to, or attended with, a kind of palsy of the intestines: to be cured by fomenting the abdomen with wine in which aromatics have been boiled, and drinking a little of the same when the pulse is slow and the body cocl: or in this way by the cold water, when the patient inclines to be hot or feverish. By putting the feet into cold water, the whole body is cooled; and the blood, chilled by this operation, occupying a less space in the coats of the intestines, may allow of an easier secretion into their cavities: and if a considerable quantity of air in the guts conduces to the disease, by this coldness it may be more condensed ; and the intestine, hitherto strained by its rarefaction, now contracting, may be better able to perform its office. The cold bath is the best cure of that difficulty of making water, which is caused by a too long retention of urine. Immersion in cold water was used by the ancients in ardent fevers; and it has been practised, even in this cold climate, without any bad consequences, particularly by a hardy empiric on his mother, a lady well stricken in years, with notable success : so that there was less room for objections to this practice in the present case, where the patient was young and strong, and the fever symptomatic, especially when the disease seemed desperate without it.

"I shall add nothing further, by way of apology for this method, and leave the reader to choose for himself which of the conjectures, thrown together in the preceding paragraph, to impute the cure to: it may be owing to a combination of some of them, or perhaps to others, which the ingenious may think of, and I have omitted.

"I might add some cases akin to the one I have set down at large, in which the same practice was attended with very good effects (such as easing pain, giving strength, carry. ing off the sickness and romiting, \&c.), even where it did not procure passage immediately : but I shall content myself with subjoining a very extraordinary one, not on account of any affinity betwixt the diseases, but because the surprising efficacy of this application in opening the body appears in it. It was transmitted to me by my friend Dr. Pringle, physician to the British army, who had advised $\mathrm{Mr}$. Catherwood, surgeon to Onslow's regiment, to make the experiment. The following is a copy of his letter to the doctor:-

" ' One Laurence, a soldier in Brigadiergeneral Onslow's regiment, after a slight intermittent, which was carried off by a vomit and a few bitters, was seized with an obstinate constipation, which lasted, in spite of all the means I possibly could think of, from the 27 th of September to the 8th of November following, before a stool could be procured, which at last was obtained by the following experiment. On the 8th of November, about noon, a clyster of water-gruel, with two ounces of soft soap, was first injected; in a quarter of an hour after I ordered him to be taken out of bed, stripped mid-thigh, and to be led about the room by two of his fellow-soldiers. At which time I dashed his legs and thighs every half minute with cold spring-water, which I found surprised him much, and seemed to give sensible shocks to the whole habit. About the tenth minute from the first sprinkling he began to drop some excrement: at the seventeenth minute a pretty tolerable stool came away, rather a soft than a hard one; which surprised me the more, as he had been so long without one. Finding him at this time weak, and fatigued with walking so much about, I ordered him to be wiped dry, put to bed, and a porringer of warm broth to be given, and covered up close. He continued in this way till ten o'clock at night, at which time he had another stool, which was succeeded by two more involuntary ones before morving; the whole making a pretty considerable evacuation. It must be observed, that through the whole of this case the patient had no complaint of pain, no vomiting, but an extraordinary gross evacuation by urine of a chocolate colour. Sometimes he would take his nourishment pretty well, at other times obstinately refuse it. All along he seemed to be stupid, and is at this time so emaciated and weak, that, without some extraordinary turn, I must think him still incurable. If you can think of anything that may be of further service in this case, I shall with pleasure observe your commands, being, \&c.

" ' Bruges, Nov. 11, 1742.

66 W. Catherwood.

" 'N. B. - He is about forty-five years of age." " 